\title{
Screening for Dementia: Family Caregiver Questionnaires Reliably Predict Dementia
}

\author{
Marilee Monnot, PhD, Meg Brosey, MS, and Elliott Ross, MD
}

Introduction: Because of increasing numbers of patients with diseases that cause dementia, primary care physicians must use efficient assessment procedures in their clinics. Important advantages of screening for dementia include determination of the patient's cognitive capacity to participate competently in his/her own medical care and early diagnosis, which enables administration of medications that preserve some cognitive functions.

Methods: A study was conducted to determine whether questionnaires completed by a family caregiver about a patient could differentiate between those with dementia and those with other neurological disorders that do not cause dementia. Clinical and demographic information gleaned from more than 330 consecutive multidisciplinary outpatient dementia clinic assessments were entered into an Institutional Review Board-approved database and analyzed post hoc to answer several research questions.

Results: Three questionnaires completed by family caregivers about patients were able to differentiate reliably between patients with dementia with a variety of degenerative disorders and patients without dementia with other neurological disorders that often are mistaken for dementia. When these questionnaires are combined with a patient test (Mini-Mental State Examination), an accurate prediction of which patients suffer from a true degenerative disease that causes dementia was robust (effect size of $R^{2}=0.81, P<.0001$ for the multiple logistic regression analysis).

Discussion: These instruments assist the primary care physician to determine which patients seem to suffer from a disease that causes dementia and need further assessment by the physician or at a specialized dementia clinic. The ultimate goal is to assure that patients receive appropriate medical management as early in the disease process as possible. ( $\mathrm{J}$ Am Board Fam Pract 2005;18:240-56.)

With the aging of 75 million baby boomers, ${ }^{1-4}$ primary care physicians (PCPs) are bracing for an increase in numbers of patients diagnosed with Alzheimer disease $(\mathrm{AD})$ and related dementias. Current estimates of $\mathrm{AD}$ prevalence vary from $4.5 \%$ to $16.8 \%$ for patients older than 65 years; however, epidemiologic studies indicate future prevalence and dementia-related resource usage may be higher than current estimates. ${ }^{5}$ Some have questioned the efficacy and public health need for large-scale screening of the elderly for dementing illnesses. ${ }^{6}$ However, the lay press is replete with warnings that "dementia often goes undiagnosed in primary care

Submitted, revised, 22 February 2005.

From the Departments of Neurology (MM, ER), Information Technology (MB), University of Oklahoma Health Sciences Center College of Medicine, and Veterans Affairs Medical Center (ER), Oklahoma City, OK.

Conflict of interest: none declared.

Corresponding author: Marilee Monnot, PhD, University of Oklahoma Health Sciences Center, College of Medicine, Department of Neurology, 711 Stanton L. Young Boulevard, Suite 215, Oklahoma City, OK 73104 (e-mail: marileemonnot@ouhsc.edu). settings, $" 7$ and these warnings receive support from evidence-based studies. ${ }^{8}$

There are distinct advantages to screening for dementia at the primary care level of practice. Early diagnosis enables the physician to administer medications that slow disease progression ${ }^{9,10}$ and to assist the patient and family members in planning for diminished capacity while the patient is still able to participate in decision-making. ${ }^{11}$ In addition, primary care physicians need to know whether their patients can give accurate histories or can be relied on to participate in their own medical care, including taking medications as directed. Patients with dementia often have intact but superficial social and communication skills that, if accompanied by loss of insight, may mask their cognitive decline from casual observers and interfere with their ability to assist the physician in their medical care. In addition, physicians are concerned about offending less insightful patients regarding their current cognitive deficiencies and about obtaining confidential information from family members. Physicians also must weigh how much clinic time is needed to 
administer screening instruments that assess a patient's cognitive and behavioral status against the benefits that accrue from these assessments in regard to patient care. From the medical consumer's point of view, the stress of caregiving encourages family members to seek a reliable way to alert the physician of important behavioral changes in the demented patient. ${ }^{2,12}$ In addition, it is now generally accepted that family caregivers, especially those who live with the patient, can provide important information about recent cognitive and behavioral changes in the patient that aid in the differential diagnosis of degenerative diseases that cause dementia. $^{13-15}$

With these issues in mind, we developed a set of family caregiver questionnaires, based on our experience in diagnosing patients in a University-based clinic for memory loss and dementia. The questionnaires used in assessments consist of several that are recommended by the National Alzheimer's Coordinating Center (NACC), but some were modified for use by untrained family caregivers.

For example, the Clinical Dementia Rating $(\mathrm{CDR})^{16,17}$ is very useful when assessing patients for dementia. To properly administer this instrument, up to 10 hours of training is needed on the Washington University School of Medicine Alzheimer's Disease Research Center web site. ${ }^{18}$ It is a highly reliable clinical staging assessment for dementia that uses semistructured interviews of the patient and a reliable collateral source. It is conducted by a clinician who rates 6 domains of cognitive and functional performance: memory (recent and long-term), orientation, judgment and problem solving (including insight), community affairs, home and hobbies, and personal care. Each domain is scored, and an overall CDR score is arrived at by a standard algorithm to stage the patient's level of impairment: 0, no impairment; 0.5 , very mild impairment; 1 , mild dementia; 2 , moderate dementia; and 3, severe dementia. After using this instrument on approximately 400 patients/caregivers, we noticed a set of symptoms, including behavioral abnormalities for each of the 6 categories, that were mentioned consistently by family members of patients with dementia during the interview process. We turned those observations into a caregiverfriendly questionnaire for family members to fill out about the patient during the multidisciplinary assessment. In this modified CDR, 5 concrete examples of possible patient behaviors were added to each of the 6 major and 2 minor categories of patient functioning. The first 3 statements in each category were clear signs of dementia, and the last 2 could be observed in either mild impairment (CDR level 0.5 ) or clinical depression. For all 8 categories, a score of " 1 " was assigned to each of the first 3 symptoms marked by the caregiver, whereas the last 2 symptoms were scored only 0.5 even if both were marked. Scores for all the categories were totaled and divided by 8 to arrive at a mean score based on family member observations of the patient (Appendix). This is not the scoring algorithm used in the original clinical interview, but it served our purpose in screening new patients for dementia. In addition, results of administering and scoring the CDR clinical interview in the traditional manner were recorded so comparisons could be made at a later date.

Another questionnaire, the Frontal Behavioral Inventory (FBI), ${ }^{19}$ was formed from lists of symptoms common to frontotemporal dementias in which behavioral and personality changes are prominent. The original FBI has now been standardized and is more effective in detecting frontotemporal dementias than traditional neuropsychological testing. ${ }^{20-22}$ We adapted the list of symptoms for use by poor readers and those with limited education; the family caregiver rates the patient on each of 24 frontotemporal symptoms using a 4-point Likert scale (0, no symptoms; to 3, severe symptoms). These scores are totaled for the entire instrument, with a maximum score of 72 .

A third instrument, the caregiver burden versus satisfaction questionnaire, ${ }^{23}$ reveals positive and negative attitudes about caregiving. It can also be used in statistical analyses if an individual index score is derived by subtracting the total burden score from the total satisfaction score. Thus, if the satisfaction score is much larger than the burden score, caregiving is not stressful, and the index score will be large. If burden is similar to satisfaction, caregiving is stressful, and the index number will be a small positive or negative number. The burden score alone also gives important information about how stressful it is for family members to care for the patient.

The Yesavage Geriatric Depression Scale ${ }^{24}$ was used to assess the elderly spouse caregiver who filled out the forms about the patient. If a spouse is suffering from significant depressive symptoms $(>9$ of 15 points on the shortened form), then the reli- 
ability of the patient questionnaire information may be suspect, because depressed persons often see the world as more negative than it really is. Therefore, the patient may not be as ill as the caregiver reports. Five such cases were encountered. They were not included in analyses reported here, and the caregivers were referred for evaluation and treatment of depression.

Another instrument used during the multidisciplinary assessment was a caregiver stress symptom inventory (stress warning signals) adapted from the Stress Perception Scale by Herbert Benson at Harvard University (unpublished). Family caregivers simply checked their current symptoms of distress according to 6 domains: physical, emotional, spiritual, behavioral, cognitive, and relational. The number of symptoms was totaled to yield the caregiver's stress score. This instrument alerted the medical team about the family caregiver's potential health risks from excessive stress.

After observing the apparent efficacy of these instruments in the clinic, we pursued more objective data by conducting an accuracy study of these questionnaires in screening for dementia. The hypothesis tested was formulated after questionnaire development and use but before data collection. The explicit purpose was to formulate a screening device for use in primary medical care settings, to aid in the early diagnosis of diseases that cause dementia.

\section{Methods}

Data in the University of Oklahoma Health Sciences Center (OUHSC) dementia database is compiled continuously from medical records of consecutive patients assessed and treated at the University of Oklahoma Physicians Center for Memory Loss and Dementia (CMLD). Patients seen in this clinic must be referred by a primary care physician (PCP) or another physician who suspects that the patient may have a disease that causes dementia. However, not all patients evaluated in this clinic have a true degenerative disease that causes dementia; $\sim 17 \%$ of these referred patients have been found to suffer from other neurological diseases that share some of the symptoms of dementia (meningitis, stroke, depression, low levels of thyroid hormone, low levels of vitamin $B_{12}$, overmedication toxicity, etc). Our de-identified, Institutional Review Board-approved database contains information on more than 330 subjects who have agreed to participate (CDR level $\leq 1.0$ ) or whose participation is approved by the patient's designated Power of Attorney. Using the Teleform information system (Verity Inc., Sunnyvale, CA), medical record forms are scanned to enter relevant medical information directly into the database that includes demographic, neurobehavioral testing, neurological examination, and diagnostic information. JMP Statistical Discovery software (SAS Institute, Cary, NC) was used to analyze the data. In addition to specific diagnoses, patients were classified as: (1) demented ( $\mathrm{AD}$, Huntington disease, Lewy body disease, Pick disease, frontotemporal, corticobasal ganglionic degeneration, vascular dementia) or (2) not demented (age-associated cognitive decline, mild cognitive impairment, depression, stroke, seizures, encephalitis, overmedication toxicity, or other nondegenerative neurological disorders). This was done for the purpose of answering the research question: "Can questionnaires completed by a family caregiver about the patient differentiate between patients with dementia and patients without dementia but with other neurological disorders?"

Traditional clinical interviews were conducted with family members by the primary author, especially focusing on clarification of inconsistencies in their questionnaire answers. All caregiver questionnaire results were compared with a cognitive screening instrument administered to the patient; the Mini-Mental State Examination (MMSE) is a widely used and accurate predictor of cognitive impairment among differing racial groups. ${ }^{25,26} \mathrm{Al}$ though conflicting data exist regarding the diagnostic efficacy of combining family questionnaires with direct patient assessment, it seems that the choice of instruments and caregiver characteristics make a difference in the accuracy rate. ${ }^{27-29}$ Information from CMLD questionnaires was subjected to statistical analyses in relation to each patient's diagnosis and dementia status, arrived at from our multidisciplinary assessments. ${ }^{30}$

\section{Statistical Tests Used}

Continuous variables, such as patient age, were subjected to regression analyses if the variables were parametric. Categorical (nominal) variables, such as dementia status (yes or no), were analyzed using both analysis of variance (ANOVA) and logistic regression methods. Calculations completed automatically in the JMP statistical program for 
ANOVAs, such as "CDR $\times$ dementia," include the number of respondents for each level of the categorical variable, the mean of the responses, the standard error (a pooled estimate of error variance), and figures for the lower $95 \%$ and upper $95 \%$ of scores for each level. Thus, behaviorally relevant information about cutoff points for each categorical variable is available.

When analyzing the ability of several variables to predict a single effect, the whole model fit computation is similar to the ANOVA for continuous responses; its resulting table shows tests that compare the whole model fit to the model that omits all the regressor effects except the intercept parameters.

The computed $R^{2}$ figure describes how much of the measured effect can be attributed to the variable(s) tested. The effect size is measured by several statistics $\left(R^{2}, r^{2}, \eta^{2}, g, r\right.$, and $\left.d\right)$ and the results range from 0 (no association) to 1 (complete association). The squared parameters estimate what percentage of the variability is explained by the data; ie, an $R^{2}$ of 0.36 indicates that $36 \%$ of the variance is explained by the statistical analysis. $R^{2}$ values between 0.01 to 0.09 are considered small effect sizes, values between 0.09 and 0.25 are considered medium effect sizes, and values $>0.5$ are considered large effect sizes. ${ }^{31} R^{2}$ Adjusted is a more conservative strength of association measure than $R^{2}$ because it subtracts out the statistical variance related to the SEM. In this study, logistic regression was used to compute the final effect; it fits nominal $Y$ responses to a linear model of $X$ predictors. A nominal model rarely has a high $R^{2}$, but it is the best overall estimate of the effect size of the relationship between variables analyzed in the study.

\section{Results}

Information about percentages of each category/ diagnosis from the entire OUHSC database is summarized in Table 1 . All variables used in this study were parametric. Expected numbers of patients with and without dementia, classified according to sex or ethnic group, were found, indicating that the database information is similar to other published data from specialized dementia clinics, ${ }^{32,33}$ and to Oklahoma population figures from the latest census $^{34}$ (except for Native Americans who are often seen in their own tribal hospitals in Oklahoma). Neither ethnic group $(P<.86)$ nor sex $(P<.64)$
Table 1. University of Oklahoma Health Sciences Center Dementia Database Categories with Demographic Percentages and Comparisons with State Census Figures

\begin{tabular}{lc}
\hline Category & $\begin{array}{c}\text { University of Oklahoma Database/ } \\
\text { 2000 Oklahoma Census* (\%) }\end{array}$ \\
\hline Female & $63 / 50.9$ \\
Male & $37 / 49.1$ \\
White & $87 / 80.3$ \\
African American & $8 / 8.3$ \\
Native American & $4 / 11.4$ \\
Asian & $1 / 1.7$ \\
Demented & 73 \\
Not demented & 27 \\
Alzheimer disease & 27 \\
Frontotemporal/Lewy body & 25 \\
Corticobasal ganglionic & 11 \\
Vascular dementia & 6 \\
Huntington disease & 4 \\
Mild cognitive impairment & 9 \\
Depression & 8 \\
Other neurological diseases & 10 \\
\hline
\end{tabular}

* Does not equal $100 \%$ because of mixed racial identity reported by citizens.

differentiated between patients with and without dementia. However, patients with dementia in our database were significantly older than patients without dementia $(P<.007)$. The mean age of the patients with dementia was 72.3 years, and the mean age of patients without dementia was 66.4 years, but the effect size ( $R^{2}$ Adjusted) of the ANOVA analysis "demented $\times$ age" was negligible at 0.04 . Table 2 summarizes statistical analyses of these dependent and independent variables, and Table 3 summarizes analyses of the relationships between covariates in the study.

Another ANOVA analysis showed that MMSE scores were significantly different by dementia status despite a very wide range of educational achievement among database participants (6 to 20 years of formal education). Of patients diagnosed as demented, $95 \%$ scored 20 points or less and $95 \%$ of patients without dementia scored more than 24 points (Table 2). However, the effect size $\left(R^{2} \mathrm{Ad}-\right.$ justed $=0.28)$ is only moderate and reflects the poor ability of MMSE to detect diseases that cause dementia that begin with predominantly behavioral and personality changes (eg, Lewy body disease, frontotemporal dementias, etc) as opposed to memory deficits. ${ }^{35}$ 
Table 2. Results of ANOVA and Linear Regression Analyses of the Dependent and Independent Variables

\begin{tabular}{|c|c|c|c|c|c|}
\hline Statistical Analysis & $P$ & $R^{2}$ Adjusted & $F$ Ratio & $\begin{array}{l}\text { Patients with } \\
\text { Dementia }\end{array}$ & $\begin{array}{c}\text { Patients } \\
\text { without Dementia }\end{array}$ \\
\hline Demented $($ yes or no) $\times$ patient age & .007 & 0.03 & 7.3 & $\begin{array}{l}72.2 \pm 1.0 \\
\text { (patient age) }\end{array}$ & $\begin{array}{l}66.7 \pm 1.7 \\
\text { (patient age) }\end{array}$ \\
\hline Demented $\times$ MMSE & $<.0001$ & 0.28 & 72.4 & $\begin{array}{r}18.7 \pm 0.5 \\
(\mathrm{MMSE})\end{array}$ & $\begin{array}{l}26.1 \pm 0.08 \\
(\mathrm{MMSE})\end{array}$ \\
\hline Demented $\times$ modified CDR & $<.0001$ & 0.49 & 191.6 & $\begin{array}{c}1.64 \pm 0.05 \\
\text { (modified CDR) }\end{array}$ & $\begin{array}{c}0.35 \pm 0.1 \\
\text { (modified CDR) }\end{array}$ \\
\hline Demented $\times$ traditional CDR & $<.0001$ & 0.50 & 206.5 & $\begin{array}{c}1.63 \pm 0.05 \\
\text { (traditional CDR) }\end{array}$ & $\begin{array}{c}0.33 \pm 0.17 \\
\text { (traditional CDR) }\end{array}$ \\
\hline Demented $\times$ modified FBI & $<.0001$ & 0.11 & 15.6 & $\begin{array}{l}22.1 \pm 1.4 \\
\text { (modified FBI) }\end{array}$ & $\begin{array}{c}11.4 \pm 2.3 \\
\text { (modified FBI) }\end{array}$ \\
\hline Demented $\times$ Burden & .002 & 0.11 & 10.5 & $\begin{array}{c}19.9 \pm 3.3 \\
\text { (burden score) }\end{array}$ & $\begin{array}{c}43.3 \pm 6.4 \\
\text { (burden score) }\end{array}$ \\
\hline Demented $\times$ UCLA $^{*}$ & .10 & 0.01 & 2.7 & & \\
\hline Demented $\times$ Yesavage* & .15 & 0.02 & 2.1 & & \\
\hline Demented $\times$ Beck $^{*}$ & .56 & 0.03 & 1.1 & & \\
\hline Demented $\times$ stress $^{*}$ & .15 & 0.03 & 2.1 & & \\
\hline
\end{tabular}

* Not significant.

Modified CDR, Clinical Dementia Rating scale: Y, yes; N, no; FBI, Frontal Behavioral Inventory; Burden, Caregiver Burden score; Yesavage, Yesavage Depression Rating Scale; Beck, Beck Depression Inventory; UCLA, UCLA Neuropsychiatric Inventory; MMSE, Mini-Mental State Exam.

Several questionnaires were used to elicit information from family caregivers about themselves and about behavioral changes in the patient during CMLD multidisciplinary diagnostic assessments: the modified CDR, modified FBI, Caregiver Burden and Satisfaction Scale, UCLA Neuropsychiatric Inventory, ${ }^{36}$ Beck Depression Inventory ${ }^{37,38}$ (for use with younger caregivers), Yesavage Geriatric Depression Scale, ${ }^{24}$ and the Stress Warning Signals. Instruments used that were not changed or adapted for use at the CMLD include the UCLA Neuropsychiatric Inventory, ${ }^{36}$ Beck Depression Scale, ${ }^{37,38}$ and Yesavage Depression Scale. ${ }^{24}$
Again using ANOVA, scores derived from the modified CDR were significantly different for neurology patients with and without dementia. Of patients with dementia, $95 \%$ scored $\geq 1.6$; of patients without dementia, $95 \%$ scored of $\leq 0.4$, as rated by their family members (Table 2). These figures were the same for the traditional CDR staging algorithm scores. The scores of the modified CDR were compared with the traditional CDR; Pearson $\chi^{2}$ analysis showed no significant difference between the 2 scoring systems $(P=.75)$ on any of the 4 staging levels: level $0(P=.10)$; level $.5(P=.17)$; level 1 $(P=.33)$; level $2(P=.32)$; level $3(P=.17)$. A

Table 3. Linear Regression Analyses Describing Relationships Between Covariates

\begin{tabular}{|c|c|c|c|c|c|}
\hline \multirow[b]{2}{*}{ Statistical Analysis } & \multirow[b]{2}{*}{$P$} & \multirow{2}{*}{$\begin{array}{c}R^{2} \\
\text { Adjusted }\end{array}$} & \multirow[b]{2}{*}{$F$ Ratio } & \multicolumn{2}{|c|}{ Test Results } \\
\hline & & & & Demented & Nondemented \\
\hline Modified CDR $\times$ MMSE & $<.0001$ & 0.52 & 95.4 & CDR level $3=$ mean MMSE 11 & CDR level $0=$ mean MMSE 27 \\
\hline Modified CDR $\times$ Burden & .0009 & 0.18 & 5.2 & $\begin{array}{l}\text { CDR level } 3=\text { mean Burden } \\
\text { index } 5\end{array}$ & $\begin{array}{l}\text { CDR level } 0=\text { mean Burden } \\
\text { index } 28\end{array}$ \\
\hline Modified CDR $\times$ modified FBI & $<.0001$ & 0.25 & 10.8 & $\begin{array}{l}\text { CDR level } 3=\text { mean FBI } \\
\text { score } 37\end{array}$ & $\begin{array}{l}\text { CDR level } 0=\text { mean FBI } \\
\text { score } 8\end{array}$ \\
\hline MMSE $\times$ Burden & $<.0001$ & 0.2 & 19.1 & $r=0.31, P<.018$ & $r=0.74, P<.001$ \\
\hline MMSE $\times$ modified FBI & $<.0001$ & 0.26 & 41.8 & $r=-0.44, P<.0000$ & $r=-0.44, P<.017$ \\
\hline Modified FBI $\times$ Burden & $<.0001$ & 0.37 & 39.0 & $r=-0.49, P<.0002$ & $r=-0.8, P<.0003$ \\
\hline
\end{tabular}

CDR, Clinical Dementia Rating scale; FBI, Frontal Behavioral Inventory; Burden, Caregiver Burden score; MMSE, Mini-Mental State Exam. 
linear regression of the 2 scoring systems resulted in a highly significant association $\left[R^{2}\right.$ Adjusted $=$ $0.83, P<.0001]$. However, the statistical correlation between the 2 scoring systems earned by patients without dementia $\left(r=0.51 ; R^{2}=0.26\right)$ was not as robust as the correlation of the scores earned by patients with dementia $\left(r=0.84 ; R^{2}=0.71\right)$.

Analyses of 2 other questionnaires showed scores that were significantly different by dementia status (Table 2). For the modified FBI questionnaire, $95 \%$ of patients with dementia scored 19 or more points, whereas $95 \%$ of patients without dementia scored less than 7 points. For the Caregiver Burden and Satisfaction Questionnaire, 95\% of caregivers of patients with dementia had index scores of 26 or less, whereas $95 \%$ of caregivers of patients without dementia had index scores of 30 points or more. However, no significant ability to predict dementia status was found in 4 of the questionnaires used in our clinic assessments: the UCLA Neuropsychiatric Inventory, Beck, Yesavage, and Stress Warning Signals (Table 2). One explanation for the unexpected poor performance of the UCLA was that many family members stated it was "too hard to read" (only 117 family caregivers completed that questionnaire).

Analyses of the association between one measure of caregiver observations (modified CDR) and the MMSE are also meaningful. Linear regression analysis of CDR $\times$ MMSE for all patients showed a significant association (Table 3 ). But this negative correlation was significant for patients with dementia only $\left(r=-.70 ; R^{2}=0.49 ; P<.0000\right)$. No significant correlation was found between CDR and MMSE scores for the patients without dementia $\left(r=-.23 ; R^{2}=0.05 ; P=.065\right)$.

Analyses of the relationships among the instruments noted above indicates that the patient screening instrument (MMSE) and the family questionnaires (modified CDR, modified FBI, and the Burden score) are all significantly associated but that each individual questionnaire assesses different aspects of patient behavior (Table 4). They may each be used independently to predict dementia. However, their joint use provides much greater predictive power.

We subjected our data to a Nominal Logistic Regression (whole model fit) to determine how well the combined questionnaires and the MMSE predicted dementia. Predictors that contributed significantly to the clinical categorization included:
(1) MMSE, (2) modified CDR, (3) modified FBI, and (4) Caregiver Burden score; use of these 4 variables in the analysis resulted in the most robust effect size $\left[R^{2}\right.$ Adjusted $=0.81, d f=4, \chi^{2}=39.9$, $P<.0001]$. This very large effect size indicates that the combination of instruments reliably differentiates between patients with and without dementia with a high degree of accuracy, explaining $81 \%$ of the variance in the data. Each individual instrument, or variable seems to be insufficient to predict reliably whether a patient is demented or not, but their combined use predicts very accurately which patients will later be diagnosed with a degenerative disease that causes dementia (see Table 2 for $R^{2}$ effect sizes).

\section{Discussion}

This complete instrument (caregiver questionnaires and a patient test) reliably detects patients who are demented, even in comparison with other neurologically ill patients. The behavioral and cognitive differences between patients frequently seen in primary practice settings (mildly demented and neurologically healthy) are easier to detect than between patients with dementia and those with other neurological disorders. ${ }^{39}$ Therefore, this instrument may be useful for PCPs who must decide which patients need referral for specialized assessment and disease management or must manage such patients themselves when specialized dementia clinics are not available/acceptable to some patients. Although general screening of all primary practice patients is not cost-effective, this instrument allows concerned family members to alert the patient's PCP about a decline in competence and/or disturbing changes in personality that herald certain diseases that cause dementia. Often these symptoms are not displayed in the context of the primary care office; family feedback about such changes is the only way to detect early stages of diseases that cause dementia, when specialized treatment is most effective.

At present, the packet named Dementia Screening Questionnaire may be used in clinic waiting rooms when family members need to communicate with the physician about changes in the patient's behavior, memory, and/or judgment (Appendix). Support staff or nurses can easily score these questionnaires in approximately 5 minutes. If significant scores are noted on any of the questionnaires, then 
use of time to administer the MMSE (approximately 5 to 10 minutes) by a physician or nurse may be warranted. This screening instrument can be used efficiently by a PCP to determine the patient's need for further detailed evaluation.

This study describes a post hoc analysis of a family caregiver questionnaire designed for use in a specialized dementia clinic in which patients are screened and referred by PCPs. Although this instrument has not been formally assessed in a primary care setting, the authors felt the urgency of providing patients with dementia with proper treatment as early as possible in the disease process warranted disclosure of these results now. It is a reliable tool that complements other assessments used by the PCP. This screening instrument is not intended for general use with every patient seen in a primary care setting, but it can be used when the patient's behavioral changes warrant extra assessment. Including the family (spouse or adult children who know the patient very well) in the assessment process is not without problems, but it often yields very important information about subtle changes in cognition and behavior that cannot be collected in any other way. Acceptability of the family caregiver questionnaire for each private practice setting has yet to be determined and may vary by the ability of family members to read and understand the judgments they must make about the patient. However, the educational levels represented in the OUHSC dementia database range from 6 to 20 years; therefore, this instrument seems to be sufficient and tolerable for those with restricted reading comprehension. Thus, this instrument package (including the MMSE) is another resource available to physicians who treat those at risk for diseases that cause dementia: middle-aged and elderly patients.

The instrument's main limitation is that it cannot determine which disease the patient suffers from. That differentiation requires a detailed multidisciplinary assessment by the PCP or in a specialized dementia clinic. Further analyses of this instrument should include use in a primary care setting and could include a blinded scoring of the questionnaire, separate from its use within the specialized dementia clinic setting where its diagnostic use has been demonstrated. However, the objective nature of the scoring of all questionnaire responses (either yes or no to each item) means that the questionnaire results are not likely to change. Refinements of the sensitivity of individual questions and their acceptability to most levels of reading comprehension are planned for the future. In the meantime, this instrument may be useful to PCPs who must manage the myriad health needs of large numbers of elderly patients. 
Appendix

Dementia Screening Questionnaire and Scoring and Results Sheet

\section{PART 1 - MEMORY LOSS \& GENERAL FUNCTIONING}

Please darken all squares that describe your loved one's current behaviors:

\section{Recent Memory}

$\square$ poor recall of recent events, or repeatedly forgets appointments or other important obligations.

$\square$ repeats statements or questions during same conversation (can't remember prior statements and/or questions by self or others; can't seem to learn anything new).

$\square$ forgets familiar names or faces (can't recall names and/or faces of spouse, children, close associates).

$\square$ word-finding disorder (often can't think of the word to use in a sentence, especially nouns or names).

losing train of thought (often forgets what he/she is talking about in the middle of a conversation).

\section{Long-term Memory}

poor recall of important personal details (forgets own date of birth/age/marriage, death of spouse, etc.).

confused chronology of life (confused as to who is the oldest sibling/child, or the year of important events).

$\square$ poor recall of current age of children and/or spouse (forgets year of birth or approximate age).

poor recall of history (can't remember details of important historical events that were known previously).

$\square$ doesn't pay attention to news anymore (used to be interested and knowledgeable).

\section{Orientation}

$\square$ confused about personal identity (can't remember married name, or one's role in the current family). repeatedly confused about date/time (can't determine what month or year it is; confuses night \& day).

confused about location (can't identify where they are, or asks to "go home" when they are at home).

any episodes of being lost (confused in familiar areas; lost in a parking lot for more than $15 \mathrm{~min}$.).

$\square$ asks family members date or time repeatedly, rather than figuring it out independently.

\section{Judgment \& Problem Solving}

$\square$ poor complex task completion (trouble doing 2 things at once, such as writing a phone message while talking; trouble completing tasks with a sequence of steps such as baking a cake or changing oil in the car).

$\square$ poor social skills (embarrassing or inappropriate behaviors or speech, or unusual anger outbursts). poor procedural memory (trouble remembering how to do something, or how to start a familiar task). employment or home management problems (reprimands regarding work, incompetence in home tasks). $\square$ apathy about task demands or competence decline (reduced ability to notice chores, tasks, problems).

\section{Insight and Self Awareness}

$\square$ poor insight about memory deficits (denial after others have confronted patient with memory problems). $\square$ constantly misplaces or loses personal items (even when family establishes permanent storage spots).

$\square$ suspecting thievery (sure that someone is stealing items that have been misplaced).

blames others when items are lost (says spouse or child misplaced missing wallet, keys, purse, etc.). refuses to accept responsibility for consequences of decline in task competence (apathetic).

\section{Community Affairs \& Concentration}

$\square$ recent onset of money management problems (forgets to pay bills; pays too much or pays twice; sends money to sweepstakes, organizations, or charities indiscriminately).

$\square$ frequent shopping problems (forgets about needed items; purchases wrong items; buys same items repeatedly; refuses to go shopping when it is necessary).

making change mistakes (hands clerk a $\$ 5$ bill when the price is $\$ 10$; unable to compute change). math problems (cannot or will not do simple math computations any more, such as doubling a recipe). 
apathy regarding financial affairs (little interest in bills, income, budgeting).

\section{II $\underline{\text { Home + Hobbies }}$}

poor driving skills (recent increase in accidents/tickets; weaving in lanes; changing lanes without signaling; tailgating or poor judgment of distances; stepping on gas pedal when braking is required).

$\square$ lack of safety (turns on kitchen stove burners but forgets them; poor judgment about danger; frequent falls in familiar areas; medication mistakes or confusion about dosages; refusal to take needed medications).

$\square$ poor chore completion (can't complete familiar tasks; poor recognition of important needed chores). $\square$ inadequate cooking or meal preparation (loss of motivation to prepare complete meal; forgetting recipes).

$\square$ abandonment of hobbies (withdrawal from familiar activities or social events; reduction in competence).

\section{Personal Care}

poor hygiene (reluctance to bath, shave, brush teeth; insisting bathing happened when it didn't).

$\square$ inappropriate clothing (putting on summer clothes in cold weather, or the opposite; wearing dirty or same clothes repeatedly; putting together bizarre outfits or combinations of clothing).

$\checkmark$ poor grooming (can't fix hair, wear makeup, or keep self clean; can't recognize when grooming is needed).

$\square$ apathy about hygiene or grooming tasks (can do tasks competently, and used to be careful about them).

$\checkmark$ uses poor judgment about hygiene or grooming (often doesn't notice soiled face or clothing;

brushes teeth without toothpaste; irons soiled clothing, etc.).

CLINICAL DEMENTIA RATING - modified family caregiver version

Adapted from: Berg, L. Mild senile dementia of the Alzheimer type. Mt. Sinai Journal of Medicine, 55:87-96. 1988

\section{PART 2 - BEHAVIOR AND PERSONALITY CHANGES}

\section{Apathy:}

Please mark one box in each category that describes patient's current behavior:

Patient has maintained interest in friends and social activities.

Occasionally patient loses interest in friends or daily activities.

Often patient loses interest in friends or daily activities.

Most of the time patient loses interest in friends or daily activities.

\section{Aspontaneity:}

Patient does start doing appropriate things on own initiative.

Occasionally patient does have to be asked to start doing appropriate things.

Often patient does have to be asked to start doing appropriate things.

Most of the time patient does have to be asked to start doing appropriate things.

3. Indifference, Emotional Flatness:

Patient responds to occasions of joy or sadness as much as ever.

Occasionally patient does not respond to occasions of joy or sadness.

Often patient does not respond to occasions of joy or sadness.

Most of the time patient does not respond to occasions of joy or sadness.

\section{Inflexibility:}

Patient changes mind with reason and logic.

Occasionally patient appears stubborn and rigid in thinking.

Often patient appears stubborn and rigid in thinking.

Most of the time patient appears stubbom and rigid in thinking.

\section{Concreteness:}

Patient interprets what is being said appropriately.

Occasionally patient understands only the concrete meaning of what is being said.

Often patient understands only the concrete meaning of what is being said.

Most of the time patient understands only the concrete meaning of what is being said. 


\section{Personal Neglect:}

Patient takes usual care of personal hygiene and appearance.

Occasionally patient needs prompting and assistance to be presentable.

Often patient needs prompting and assistance to be presentable.

Most of the time patient needs prompting and assistance to be presentable.

\section{Disorganization:}

Patient plans and organizes complex, multi-step activities as usual.

Occasionally patient is easily distracted/confused when planning or organizing complex activities.

Often patient is easily distracted/confused when planning or organizing complex activities.

Most of the time patient is easily distracted/confused when organizing complex activities.

8. Inattention:

Patient pays attention to what is going on in the immediate environment and on the news.

Occasionally patient seems to lose track or not follow what is going on.

Often patient seems to lose track or not follow at all what is going on.

Most of the time patient seems to lose track or not follow at all what is going on.

9. Loss of Insight:

Patient is aware of problems or changes in self, and can discuss these changes.

Occasionally patient seems unaware of problems or denies them when discussed.

Often patient seems unaware of problems or denies them when discussed.

Most of the time patient seems unaware of problems or denies them when discussed.

10. Logopenia:

Patient is as talkative as before.

Patient's amount of speech has occasionally decreased somewhat.

Patient's amount of speech has decreased noticeably and often.

Patient's amount of speech has decreased significantly all of the time.

11. Verbal Apraxia:

Patient has been talking clearly as usual, and can find words easily in conversation.

Occasionally patient has been making errors in speech with slurring or hesitation.

Often patient has been making errors in speech with slurring or hesitation.

Most of the time patient has been making errors in speech with slurring or hesitation.

12. Perservation:

Patient responds normally to remarks or actions

Occasionally patient repeats remarks or actions to a marked degree.

Often patient repeats remarks or actions to a marked degree.

Most of the time patient repeats remarks or actions to a marked degree.

\section{Irritability:}

Patient reacts to stress or frustration as usual.

Occasionally patient has been irritable or short-tempered in reacting to stress or frustration.

Often patient has been irritable or short-tempered in reacting to stress or frustration.

Most of the time patient has been irritable or short-tempered in reacting to stress or frustration.

\section{Excessive Jocularity:}

Patient has shown appropriate humor in making jokes.

Occasionally patient has been making jokes excessively or offensively, or at the wrong time.

Often patient has been making jokes excessively or offensively, or at the wrong time.

Most of the time patient has joked offensively or does not respond to others' humor now. 


\section{Poor Judgment:}

Patient has been usina qood iudament in decisions in drivina or usina machinery like the stove. Occasionally patient acts irresponsibly, neglectfully, dangerously while driving/using machinery. Often patient acts irresponsibly, neglectfully, dangerously while driving/using machinery. Most of the time patient acts irresponsibly, or patient does not drive or use machinery any

\section{longer.}

\section{Inappropriateness:}

Patient has been polite, and showed good social skills, especially in public.

Occasionally patient says/does things that are not socially acceptable (rude or childish).

Often patient says/does things that are not socially acceptable (rude or childish).

Most of the time patient says/does things that are not socially acceptable (rude or childish).

\section{Impulsivity:}

Patient has shown appropriate adult restraint in behaviors and in conversations with others. Occasionally patient has acted/spoken impulsively, without thinking about the consequences.

Often patient has acted/spoken impulsively, without thinking about the consequences.

Most of the time patient has acted/spoken impulsively, without thinking about

\section{consequences.}

18. Restlessness:

Patient's activity level has been normal (anxiety or agitation always have a realistic origin). Occasionally patient has been restless or agitated when there is no reason for nervousness. Often patient has been restless or aqitated when there is no reason for nervousness. Most of the time patient has been restless or agitated when there is no reason for nervousness.

\section{Aggression:}

Patient has shown self-control with no aggressiveness in interactions with other people.

Occasionally patient has shouted at someone aggressively or hurt them physically.

Often patient has shouted at someone or hurt them physically.

Most of the time patient shouts at people or hurts them physically.

\section{Hyper-orality:}

Patient has been drinking and eating as usual, and has not put unusual objects into mouth Occasionally patient has consumed anything in sight, or has put unusual objects into mouth. Often patient has consumed anything in sight, or has put unusual objects into mouth. Most of the time patient has consumed anything in sight, or has put unusual objects into mouth

\section{Hyper-sexuality:}

Patient has not shown any unusual or inappropriate sexual behavior.

Occasionally patient has shown unusual, excessive, or embarrassing sexual behavior.

Often patient has shown unusual, excessive, or embarrassing sexual behavior. Most of the time patient has shown unusual, excessive, or embarrassing sexual behavior.

\section{Utilization Behavior:}

Patient has shown normal restraint and respect for other's belongings.

Occasionally patient has shown unusual need to touch, feel, examine, pick up objects.

Often patient has shown unusual need to touch, feel, examine, pick up objects.

Most of time patient has shown unusual need to touch, feel, examine, pick up objects.

\section{Incontinence:}

Patient has no problems with incontinence (no urinary or bowel accidents), or patient reacts appropriately to wet or soiled underclothing and attempts to clean self promptly.

Occasionally patient ignores or is unaware of wet or soiled underclothing.

Often patient ignores or is unaware of wet or soiled underclothing.

Most of the time patient ignores or is unaware of wet or soiled underclothing. 


\section{Alien Hand:}

Patient does not make involuntary, bizarre movement with her/his hands.

Occasionally patient makes involuntary, bizarre movements with her/his hands.

Often patient makes involuntary, bizarre movements with her/his hands.

Most of the time patient makes involuntary, bizarre movements with her/his hands

Adapted from: Kertesz A. Davidson W, \& Fox H. Frontal Behavioral Inventory: Diagnostic criteria for frontal lobe dementia. Canadian Journal of Neurological Sciences $1997 ; 24: 29-36$.

\section{PART 3 - FAMILY CAREGIVER WELL-BEING}

Please indicate your degree of agreement with each statement by circling a number according to this scale: Strongly Disagree $=1$ Disagree $=2$ Neither agree nor disagree $=3 \quad$ Agree $=4 \quad$ Agree Strongly $=5$

\section{Subjective Caregiving Burden:}

1. Your health has suffered because of the care you must give. $\quad 1 \quad 2 \quad 3 \quad 45$

2. You feel isolated and alone as the result of giving care. $\quad 1 \quad 2 \quad 3 \quad 45$

3. You feel you will be unable to give care much longer. $\quad \begin{array}{llll}2 & 3 & 45\end{array}$

4. You have lost control of your life since having to give care. $\quad 1 \quad 2 \quad 3 \quad 45$

5. You are very tired as a result of giving care. $\quad \begin{array}{llll}2 & 3 & 45\end{array}$

6. You feel nervous or depressed when giving care. $\quad \begin{array}{llll}2 & 3 & 45\end{array}$

7. You feel trapped when giving care. $\quad \begin{array}{llll}2 & 3 & 45\end{array}$

8. You feel angry when you are around the relative who needs care. $\quad 1 \quad 2 \quad 3 \quad 45$

9. Your loved one seems to expect your care as the only one he/she can depend on. $\quad \begin{array}{llll}1 & 2 & 3 & 4\end{array}$

10. You don't have enough money to care for your loved one. $\quad 1 \quad 2 \quad 345$

11. You feel resentful of other relatives who could help, but do not. $\quad \begin{array}{llll}2 & 3 & 45\end{array}$ Impact of Caregiving:

12. You wish you could just leave your caregiving to someone else. $\quad 1 \quad 2 \quad 345$

13. Your social life has suffered because you are giving care. $\quad 1 \quad 2 \quad 345$

14. Because of time spent giving care, you don't have enough time for yourself. $\quad \begin{array}{llll}1 & 2 & 45\end{array}$

15. It's hard to plan things ahead when the patient's needs are so unpredictable. $\quad 1 \quad 2 \quad 345$

16. It's mostly the patient's needs that determine how your days are spent. $\quad 1 \quad 2 \quad 345$

17. Your loved one asks for more help than is necessary.

$123 \quad 3 \quad 45$ 
18. The patient affects your relationship with other family members negatively.

19. Giving care doesn't allow you as much privacy as you would like.

$\begin{array}{lllll}1 & 2 & 3 & 45\end{array}$

20. You feel uncomfortable having friends over because of him/her.

21. Giving care has interfered with your use of space in your home.

$\begin{array}{lllll}1 & 2 & 3 & 45\end{array}$

Caregiving Mastery:

22. You fit in most things you need to do in spite of the time taken by giving care. $\begin{array}{llll}1 & 2 & 3 & 45\end{array}$

23. You feel certain about what to do with your loved one, the patient.

$1 \quad 2 \quad 3 \quad 45$

24. You feel reassured knowing that as long as you are giving care

your loved one is getting proper care.

$\begin{array}{llll}1 & 2 & 3 & 45\end{array}$

25. You feel you are doing more for him/her now.

12345

26. You feel you are doing a better job caring for him/her now.

12345

27. You feel able to handle most care giving problems that arise.

12345

28. You feel pretty good about figuring out what he/she needs.

$\begin{array}{llll}1 & 2 & 3 & 45\end{array}$

29. Most things you do for him/her seem to please your loved one.

$\begin{array}{llll}1 & 2 & 3 & 4\end{array}$

30. Taking responsibility for him/her gives your self-esteem a boost.

$\begin{array}{llll}1 & 2 & 3 & 45\end{array}$

31. He/she is still being helped by most of the things you do for him/her.

$1 \quad 2 \quad 3 \quad 45$

32. The things you do keep him/her from getting worse.

$\begin{array}{llll}1 & 2 & 3 & 45\end{array}$

33. You can give care with no help, or could if need be.

$\begin{array}{llll}1 & 2 & 3 & 45\end{array}$

Strongly Disagree = 1 Disagree $=2$ Neither agree nor disagree $=3$ Agree $=4$ Agree Strongly $=5$

Caregiving Satisfaction:

34. You really enjoy being with your loved one, the patient.

$\begin{array}{lllll}1 & 2 & 3 & 4 & 5\end{array}$

35. Your loved one shows real appreciation of what you do for him/her.

12345

36. The patient's pleasure over little things gives you pleasure.

12345

$\begin{array}{lllll}1 & 2 & 3 & 4 & 5\end{array}$

37. Giving care has made you feel closer to him/her.

12345

38. It makes you happy to know that the family is caring for him/her.

$\begin{array}{lllll}1 & 2 & 3 & 45\end{array}$ 
39. You take care of your loved one because you want to rather than out of a sense of duty.

40. The patient's old self is showing through in spite of his/her current condition.

$\begin{array}{llll}1 & 2 & 3 & 45\end{array}$

41. The knowledge you are doing your best gets you through rough times.

$\begin{array}{llll}1 & 2 & 3 & 45\end{array}$

42. You do what you have to do, which is what you want to do for him/her.

$\begin{array}{llll}1 & 2 & 3 & 45\end{array}$

Cognitive Reappraisal (Traditional Caregiving ldeology):

43. A strong reason for taking care of him/her is to be true to family traditions. $\quad \begin{array}{llll}2 & 3 & 45\end{array}$

44. Giving care is a way for you to live up to religious and/or moral principals.

$\begin{array}{lllll}1 & 2 & 3 & 45\end{array}$

45. A strong reason for caregiving is to provide a good role model for your children.

12345

46. You think of the help you give as an opportunity to repay him/her.

$\begin{array}{llll}1 & 2 & 3 & 45\end{array}$

Adapted from: Lawton, M.P., Kleban, M.H., Moss, M., Rovine, M., Glicksman, A. (1989) Measuring caregiver appraisal. Journal of Gerontology: psychological sciences 44 (3) P61-P71.

Please answer these questions about yourself, as you have been feeling lately (check box): YES NO

1. Are you basically satisfied with life?

2. Have you dropped many of your activities and interests?

3. Do you feel your life is empty?

4. Do you often get bored?

5. Are you in good spirits most of the time?

6. Are you afraid that something bad is going to happen to you?

7. Do you feel happy most of the time?

8. Do you feel helpless?

9. Do you prefer to stay at home rather than going out and doing new things?

10. Do you think you have more problems with memory than most other people your age?

11. Do you think it is wonderful to be alive now?

12. Do you feel pretty worthless the way you are now?

13. Do you feel full of energy?

14. Do you feel that your situation is hopeless?

15. Do you think that most people are better off than you are?

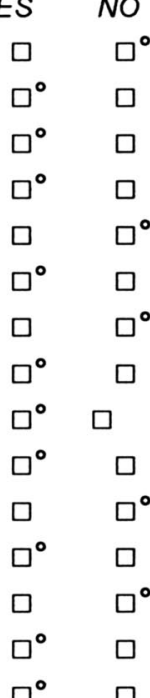

Adapted from: Sheikh JI, Yesavage JA; Geriatric depression scale (GDS): Recent evidence and development of a shorter version, in Brink TL (ed): Clinical Gerontology: A Guide to Assessment and Intervention. Binghamton, NY, Haworth Press, 1986, pp 165-273 The Haworth Press. 


\section{DEMENTIA SCREENING QUESTIONNAIRE \\ SCORING AND RESULTS SHEET}

(Do not give this form to the family member who fills out the questionnaires, or to the patient.) Patient' Name Date

Family Member Relationship to patient

CLINICAL DEMENTIA RATING (CDR) - Modified Family Caregiver Version: The first 3 items in each of the 8 categories are clear symptoms of a dementing illness, so each item marked is scored as "1". The last two sháded items in each category are symptoms of depression or possibly Mild Cognitive Impairment (often a precursor condition to dementia). These two items are scored as " 0.5 " even if both are marked by the family member. Add the scores from each of the eight categories and divide by 8 for a mean score. A mean score over 1.0 indicates a high likelihood that a dementing illness is causing these symptoms. A score of 0.5 or less may be depression and/or Mild Cognitive Impairment.

SCORE = (original published dementia staging by Berg is on page 2)

FRONTAL BEHAVIORAL INVENTORY: The first item in each of the 24 categories describes normal behavior and is not scored (no shading). The second item is scored as "1" (light shading). The third item is scored as " 2 " (medium shading). The fourth item is scored as " 3 " (dark shading). Add all scores from each of the 24 categories. Any score of 18 or more raw points $(>25 \%)$ indicates a high likelihood that a dementing illness is causing symptoms.

SCORE $=$ 172

CAREGIVER BURDEN AND SATISFACTION: For Caregiver Burden, add number of marked items under sections "Subjective Caregiver Burden" and "Impact of Caregiving" for each of the 5 columns. Then multiply the column totals by this formula: $\frac{1 \times \text { total in Column } 1=}{2 \times \text { total in Column } 2=}+\frac{3 \times \text { total in Column } 3=}{\text { TOTAL CAREGIVING BURDEN POINTS }=}+\underline{4 \times \text { total in Column } 4=}+\frac{5 \times \text { total in Column } 5=}{}$

Next, do the same calculations for the sections "Caregiving Mastery" and "Caregiving Satisfaction" to arrive at a Caregiver Satisfaction Score (do not use the 4 items under "Cognitive Reappraisal" in scoring):

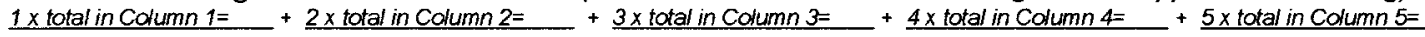
TOTAL CAREGIVING SATISFACTION POINTS =

Last, subtract Burden from Satisfaction for the index of caregiver stress: SCORE =

The larger the number, the less the burden of caregiving is compared to the satisfaction of caregiving. Any index score under 26 indicates burden and satisfaction levels are nearly equal, and caregiver stress is high. High caregiver stress is often experienced when caring for a demented relative, compared to other chronic illnesses.

YESAVAGE GERIATRIC DEPRESSION SCALE: One point is assigned for each square marked that has a SMALL CIRCLE next to it (either a 'yes' or 'no' for each question). If the caregiver/spouse scores more than 9 points out of 15 , answers to other questionnaires about the patient may not be valid, because the family caregiver may be depressed. Depression often results in judgments that are more negative than those of healthy individuals. This family member may or may not be caring for a demented family member.

SCORE $=$ 115

If scores on any of the questionnaires about the patient are in the "possible dementia range", administration of the Mini-Mental State Exam is warranted. Even for those with low educational achievement, scores under 20 are very likely to be indicative of memory decline dementia. However, patients with frontotemporal dementia often score well on that instrument in early stages of illness because they exhibit only disturbing behavior or personality changes. Specialized management of this type of dementia will be especially welcomed by the family, due to caregiver stress. 


\section{References}

1. Brookmeyer R, Gray S, Kawas D. Projections of Alzheimer's disease in the United States and the public health impact of delaying disease onset. Am J Public Health 1998;88:1337-42.

2. Ernst RL, Hay JW. The US economic and social costs of Alzheimer's disease revisited. Am J Public Health 1994;84:1261-4.

3. Gutterman E, Markowitz J, Lewis B, Fillit H. Cost of Alzheimer's disease and related dementia in managed-Medicare. J Am Geriatr Soc 1999;47:1067-71.

4. Hebert LE, Beckett LA, Scherr PA, Evans DA. Annual incidence of Alzheimer disease in the United States projected to the years 2000 through 2050. Alzheimer Dis Assoc Disord 2001;15:169-73.

5. Pressley JC, Trott C, Tang M, Durkin M, Stern Y. Dementia in community-dwelling elderly patients: a comparison of survey data, medicare claims, cognitive screening, reported symptoms, and activity limitations. J Clin Epidemiol 2003;56:896-905.

6. Boustani M, Peterson B, Hanson L, Harris R, Lohr KN; U.S. Preventive Services Task Force. Screening for dementia in primary care: a summary of the evidence for the U.S. Preventive Services Task Force. Ann Intern Med 2003;138:927-37 [summary for patients in: Ann Intern Med 2003;138:I60.].

7. Medical Study News, July 16, 2004

8. Boise L, Neal NB, Kaye J. Dementia assessment in primary care: results from a study in three managed care systems. J Gerontol A Biol Sci Med Sci 2004; 59:M621-6.

9. Fillit H, Gutterman E, Lewis B. Donepezil use in managed Medicare: effect on health care costs and utilization. Clin Ther 1999;21:2173-85.

10. Schacter A, Davis K. Guidelines for the appropriate use of cholinesterase inhibitors in patients with $\mathrm{Alz}-$ heimer's disease. CNS Drugs 1999;11:281-8.

11. Brunton SA. Alzheimer's disease: the importance of early diagnosis. Fam Pract Recertification 2001;23: 33-47.

12. Max W, Webber P, Fox P. Alzheimer's disease: the unpaid burden of caring. J Aging Health 1995;7: 179-99.

13. Ready R, Ott BR, Grace J. Validity of informant reports about $\mathrm{AD}$ and $\mathrm{MCI}$ patient's memory. Alzheimer Dis Assoc Disord 2004;18:11-6.

14. Isella V, Villa ML, Frattola L, Appollonio I. Screening cognitive decline in dementia; preliminary data on the Italian version of the IQCODE. Neurol Sci 2002; Suppl 2:S79-80.

15. Smith-Gamble V, Baiyeweu O, Perkins AJ, et al. Informant reports of changes in personality predict dementia in a population-based study of elderly African Americans and Yoruba. Am J Geriatr Psychiatry 2002;10:724-32.

16. Morris JC. The Clinical Dementia Rating (CDR): current version and scoring rules. Neurology 1993; 43:2412-4.

17. Morris JC, Ernesto C, Schafer K, et al. Clinical dementia rating training and reliability in multicenter studies: the Alzheimer's disease cooperative study experience. Neurology 1997;48:1508-10.

18. Alzheimer's Disease Research Center [homepage on the Internet]. St. Louis: Washington University; c2002 [cited 2005 May 27]. Available from: http:// www.adrc.wustl.edu/.

19. Kertesz A, Davidson W, Fox H. Frontal behavioral inventory: diagnostic criteria for frontal lobe dementia. Can J Neurol Sci 1997;24:29-36.

20. Kertesz A, Davidson W, McCabe P, Munoz D. Behavioral quantification is more sensitive than cognitive testing in frontotemporal dementia. Alzheimer Dis Assoc Disord 2003;17:223-9.

21. Kertesz A, Nadkarni N, Davidson W, Thomas AW. The Frontal Behavioral Inventory in the differential diagnosis of frontotemporal dementia. J Int Neuropsychol Soc 2000;6:460-8.

22. Kertesz A, Davidson W, Fox H. The quantification of behavior in frontal lobe dementia. In: Kertesz A, Munoz D, editors. Pick's disease and pick complex. New York: Wiley and Sons, Inc.; 1998. p. 47-67.

23. Lawton MP, Kleban MH, Moss M, Rovine M, Glicksman A. Measuring caregiver appraisal. J Gerontol 1989;44:P61-71.

24. Sheikh JI, Yesavage JA. Geriatric depression scale (GDS): recent evidence and development of a shorter version. In: Brink TL, ed. Clinical gerontology: a guide to assessment and intervention. Binghamton (NY): Haworth Press; 1986. p. 165-273.

25. Folstein MF, Folstein SE, McHugh PR. Mini-mental state: a practical method for grading the cognitive state of patients for the clinician. J Psychiat Res 1975;12:189-98.

26. Ford GR, Haley WE, Thrower SL, West CA, Harrell LE. Utility of Mini-Mental State Exam scores in predicting functional impairment among white and African American demented patients. J Gerontol A Biol Sci Med Sci 1996;51:M185-8.

27. Zanetti O, Geroldi C, Frisoni GB, Bianchetti A, Trabucchi M. Contrasting results between caregiver's report and direct assessment of activities of daily living in patients affected by mild and very mild dementia: the contribution of the caregiver's personal characteristics. J Am Geriatr Soc 1999;47:196202.

28. Broday H, Pond D, Kemp NM, et al. The GPCOG: a new screening test for dementia designed for general practice. J Am Geriatr Soc 2002;50:531-4.

29. Knafelc R, Lo Giudice D, Harrigan S, et al. The combination of cognitive testing and an informant questionnaire in screening for dementia. Age Ageing 2003;32:541-7.

30. Monnot M, Ross E. Psychosocial questionnaires accurately predict dementia. Poster presented at the 
9th International Conference on Alzheimer's Disease and Related Disorders; 2004 Jul 17-22; Philadelphia, Pennsylvania. Chicago: Alzheimer's Association; 2004.

31. Rosenthal R, Rosnow RL. Essentials of behavioral research: methods and data analysis. 2 nd ed. Boston: McGraw-Hill; 1991. p. 316-23, 350-2.

32. National Institute on Aging. Progress report on Alzheimer's disease. Bethesda (MD): National Institute on Aging; 1998.

33. Evans D. Estimated prevalence of Alzheimer's disease in the United States. Milbank Q 1990;68:26789.

34. 2000 Census Results. Washington DC: United States Census Bureau; 2000. Available from http:// www.census.gov/main/www/cen2000.html
35. Gregory CA, Orrell M, Sahakian B, et al. Can frontotemporal dementia and Alzheimer's disease be differentiated using a brief battery of tests?. Int J Geriatr Psychiatry 1997;12:375-83.

36. Cummings J. The Neuropsychiatric Inventory: assessing psychopathology in demented patients. Neurology 1997;48(5 Suppl 6):S10-6.

37. Depression in primary care: detection and diagnosis. Volume 1. Rockville (MD): Agency for Health Care Policy and Research, US Department of Health and Human Services; 1993.

38. Beck AT. Beck Depression Inventory (BDI). San Antonio: Harcourt Brace \& Company; 1996.

39. Spreen O, Strauss E. A compendium of neuropsychological tests: administration, norms, and commentary, 2nd ed. New York: Oxford University Press; 1998. 